\title{
EFEKTIVITAS PELATIHAN FAMILY CENTERED CARE TERHADAP PERSEPSI KELAHIRAN PREMATUR PADA KELUARGA BAYI PREMATUR
}

\author{
Evi Kusumahati ${ }^{1}$, Angga Wilandika ${ }^{2}$ \\ ${ }^{1,2)}$ Sekolah Tinggi Ilmu Kesehatan 'Aisyiyah Bandung \\ evikusumahati@yahoo.co.id
}

\begin{abstract}
ABSTRAK
Persalinan preterm diperkirakan menjadi faktor risiko pada 50\% dari kematian neonatal. Kelahiran prematur mengakibatkan bayi membutuhkan perawatan khusus di ruang NICU. Pendekatan perawatan berpusat pada keluarga atau dikenal dengan Family Centered Care (FCC) mampu meningkatkan kualitas hidup pada bayi dengan kelahiran prematur melalui keterlibatan keluarga secara langsung dalam memberikan asuhan terutama pasca perawatan intensif di rumah. Tujuan penelitian untuk mengetahui pengaruh penerapan FCC terhadap persepsi keluarga bayi dengan kelahiran prematur di ruang NICU RSUD Kota Bandung. Jenis penelitian preeksperimental menggunakan desain one group prepost test. Teknik pengambilan sampel random sampling yaitu keluarga bayi dengan riwayat kelahiran prematur yang memberikan probabilitas yang sama pada setiap sampel untuk terpilih dalam kelompok intervensi dengan Instrumen menggunakan kuesioner. Terdapat perbedaan yang signifikan pada persepsi keluarga terhadap kelahiran prematur sebelum dan sesudah dilakukan FCC. Hasil analisis uji beda, nilai Pearson Chi Square = 98,746 dan nilai probabilitas (Asymp. Sig) diperoleh 0,001<0,05.
\end{abstract}

Kata kunci : family centered care (FCC), kelahiran prematur, ruang NICU

\begin{abstract}
Preterm labor is estimated to be a risk factor for as many as 50\% of neonatal deaths. Premature birth causes premature babies need special care, especially care in the neonatal intensive care unit (NICU). The family-centered care approach or known as FCC is effectively used to change the perception of the family, especially the mother and reduce maternal stress during baby care in the intensive care unit. Another benefit of implementing FCC is that it helps reduce the long-term impact on premature babies. The purpose of this study was to determine the effect of Family Centered Care (FCC) application on family perceptions of infants with premature births in the NICU RSUD Kota Bandung. A one group pre-post test design was used in this study. The sampling technique in this study was used random sampling (42 families). The family perceptions of preterm baby care were measure after the implementation of the FCC. The results showed a change in family perceptions of preterm births following the FCC, classified as positive perception with a mean score of $15.0 \pm 2.2$ compared to before following the FCC of $13.2 \pm 1.8$. The results of analysis revealed the Pearson Chi Square value $=98,746$ and the probability value (Asymp. Sig) obtained $0.001<0.05$. This means that there are significant differences in family perceptions of preterm birth before and after the FCC.
\end{abstract}

Keyword: family centered care (FCC), NICU, pre-term birth 


\section{PENDAHULUAN}

Laporan WHO tahun 2012 yang berjudul Born Too Soon mengungkapkan bahwa persalinan preterm saat ini masih merupakan penyebab kematian perinatal tertinggi. Diperkirakan 15 juta bayi di dunia dilahirkan secara preterm, dan angka ini terus meningkat setiap tahunnya(Soon, 2012). Dari jumlah tersebut, 1 juta bayi meninggal per tahun dari komplikasi persalinan preterm. Bayi yang dilahirkan secara prematur meningkatkan risiko bayi meninggal dikarenakan penyebab lain, terutama dari infeksi neonatus. Persalinan preterm diperkirakan menjadi faktor risiko pada setidaknya $50 \%$ dari semua kematian neonatal (Blencowe, Cousens, Modell, \& Lawn, 2010).

Pada laporan WHO juga menuliskan bahwa Indonesia masuk dalam 11 besar (peringkat ke- 9) negara dengan tingkat persalinan preterm lebih dari 15\% kelahiran dan 10 besar (peringkat ke-5) penyumbang $60 \%$ persalinan preterm di dunia dengan angka kelahiran preterm 15,5/100 kelahiran hidup. Laporan ini juga sejalan dengan (Penelitian, 2013) yang menyatakan bahwa di Indonesia bayi prematur menyumbang 60-80 \% penyebab kematian neonatus ke-2 pada bayi usia $0-6$ hari.

Bayi yang dilahirkan sebelum mereka siap secara fisik sering membutuhkan perawatan khusus dan menghadapi risiko lebih tinggi dari masalah kesehatan yang serius. Masalah yang terjadi karena kelahiran preterm biasanya diikuti dengan berat badan kurang dari 2500 gram pada saat lahir, termasuk kemungkinan lumpuh otak, gangguan intelektual, penyakit paru kronis, dan hilangnya penglihatan serta pendengaran. Hal ini menambahkan dimensi dari disabilitas seumur hidup yang memeras biaya tinggi pada individu yang lahir secara preterm, keluarga mereka, dan institusi di mana mereka tinggal (Behrman \& Butler, 2007).

Kelahiran prematur mengakibatkan hampir semua bayi prematur membutuhkan perawatan khusus dan merupakan neonatus yang paling banyak dirawat di neonatal intensive care unit (NICU) (Hockenberry \& Wilson, 2007).

Perawat dan bidan sebagai profesi yang bertugas untuk memberikan asuhan pada klien termasuk bayi, memiliki peran yang sangat penting untuk meningkatkan kualitas hidup bayi selama proses perawatan di Rumah Sakit. Perawat dan bidan juga berperan penting dalam memfasilitasi orang tua untuk memberikan bonding attachment dan mengoptimalkan FCC melalui pemberian pendidikan kesehatan dan pendampingan berkelanjutan dari awal masuk rumah sakit sampai persiapan untuk pulang ke rumah. Hal ini bertujuan untuk memfasilitasi berbagai pencapaian peran sebagai orang tua sehingga mampu memiliki kepercayaan diri dalam mengasuh bayinya dan tidak berlebihan dalam kekhawatiran terhadap kondisi bayi meski tidak sama seperti bayi dengan kelahiran normal pada umumnya. (Bobak, Lowdermilk, Jensen, \& Perry, 2005) karena selama ini, bayi dengan kelahiran prematur masih memengaruhi persepsi keluarga berupa kekhawatiran terhadap kondisi bayi secara umum, baik secara fisik maupun psikologis. Hal ini berdampak pada kurangnya kepercayaan diri keluarga terutama orang tua untuk dapat memberikan asuhan terhadap bayinya secara mandiri tanpa menggantungkan pada peugas pelayanan kesehatan.

\section{METODOLOGI}

Jenis penelitian adalah pra-eksperimental dengan menggunakan desain one group prepost test (Riyanto, 2010). Teknik pengambilan sampel dalam penelitian ini yaitu random sampling ialah teknik penentuan sampel yang memberikan probabilitas yang sama untuk setiap sampel untuk terpilih dalam kelompok orang tua yang memiliki bayi dengan kelahiran prematur, yang diberikan penyuluhan asuhan kebidanan BBLR terutama pada masa pasca perawatan di 
rumah sakit. Analisis univariat yang bertujuan untuk menjelaskan atau mendeskripsikan setiap variabel penelitian. Variabel univariat yang akan dianalisis adalah persepsi responden terhadap perawatan bayi prematur. Analisis bivariat adalah analisis yang dilakukan pada dua variabel yang diduga berhubungan. Uji statistik dilakukan uji t-tes berpasangan bila data terdistribusi normal dan uji wilcoxon bila data tidak berdistribusi normal. Tingkat kemaknaan yang dipakai pada penelitian ini adalah $95 \%(\alpha<0,05)$.

\section{HASIL}

Uji validitas menggunakan uji split half methode untuk item pertanyaan nomor 1 sampai 25. Hasil pengujian validitas pada setiap butir pertanyaan menunjukkan bahwa seluruh item pertanyaan dikatakan valid karena memiliki nilai korelasi $\left(\mathrm{r}_{\text {hitung }}\right)>0,349\left(\mathrm{r}_{\text {tabel }}\right)$. Pada kuesioner ini, nilai validitas terendah yaitu 0,354 , sedangkan nilai validitas tertinggi yaitu 0,887 .

Tabel 1. Hasil Perhitungan Validitas Variabel Persepsi Keluarga Bayi Dengan Kelahiran Prematur

\begin{tabular}{|c|c|c|c|}
\hline Butir Pernyataan & $\begin{array}{c}\text { Corrected Item-Total } \\
\text { Correlation } \\
\left(\mathbf{r}_{\text {hitung }}\right)\end{array}$ & $\mathbf{r}_{\text {tabel }}$ & Interpretasi \\
\hline $\mathrm{P} 1$ & 0,592 & 0,349 & valid \\
\hline $\mathrm{P} 2$ & 0,503 & 0,349 & valid \\
\hline P3 & 0,527 & 0,349 & valid \\
\hline P4 & 0,438 & 0,349 & valid \\
\hline P5 & 0,556 & 0,349 & valid \\
\hline P6 & 0,633 & 0,349 & valid \\
\hline P7 & 0,725 & 0,349 & valid \\
\hline P8 & 0,731 & 0,349 & valid \\
\hline P9 & 0,592 & 0,349 & valid \\
\hline $\mathrm{P} 10$ & 0,354 & 0,349 & valid \\
\hline P11 & 0,644 & 0,349 & valid \\
\hline $\mathrm{P} 12$ & 0,731 & 0,349 & valid \\
\hline P13 & 0,558 & 0,349 & valid \\
\hline $\mathrm{P} 14$ & 0,485 & 0,349 & valid \\
\hline P15 & 0,770 & 0,349 & valid \\
\hline P16 & 0,674 & 0,349 & valid \\
\hline $\mathrm{P} 17$ & 0,792 & 0,349 & valid \\
\hline P18 & 0,395 & 0,349 & valid \\
\hline P19 & 0,887 & 0,349 & valid \\
\hline P20 & 0,767 & 0,349 & valid \\
\hline $\mathrm{P} 21$ & 0,832 & 0,349 & valid \\
\hline $\mathrm{P} 22$ & 0,832 & 0,349 & valid \\
\hline P23 & 0,419 & 0,349 & valid \\
\hline P24 & 0,832 & 0,349 & valid \\
\hline $\mathrm{P} 25$ & 0,517 & 0,349 & valid \\
\hline
\end{tabular}

$\mathrm{r}_{\text {hitung }}>0,349=$ valid 
Sementara itu, uji reliabilitas kuesioner persepsi keluarga bayi dengan kelahiran prematur dilakukan dengan menggunakan dengan menggunakan ukuran guttman split half. Hasil perhitungan reliabilitas menunjukkan bahwa nilai Koefisien Guttman Split-Half sebesar 0,747. Oleh karena itu, kuesioner persepsi keluarga bayi dengan kelahiran prematur dikatakan reliabel atau andal.(Guttman, 1945).

Penyajian pada bagian ini meliputi hasil penelitian dan analisisnya berdasarkan tujuan penelitian yang direncanakan. Hasil penelitian disajikan dalam bentuk tabel dan narasi. Keluarga yang terlibat dalam penelitian ini yaitu orang tua dari bayi dengan kelahiran prematur sebanyak 42 orang. Adapun skor perubahan persepsi keluarga bayi dengan kelahiran prematur setelah dilakukan penerapan Family Centered Care (FCC) berikut ini.

Tabel 2.Rerata Skor Persepsi Keluarga Sebelum dan Sesudah Dilakukan Penerapan FCC $(n=42)$

\begin{tabular}{lccc}
\hline $\begin{array}{r}\text { Persepsi } \\
\text { Keluarga }\end{array}$ & $\begin{array}{l}\text { Rerata Skor } \\
(\operatorname{mean} \pm \text { SD) }\end{array}$ & f & $\%$ \\
\hline $\begin{array}{l}\text { Sebelum } \\
\text { FCC }\end{array}$ & $13,2 \pm 1,8$ & & \\
\hline
\end{tabular}

Positif $18 \quad 42,9$

Negatif 24 57,1

Sesudah FCC $\quad 15,0 \pm 2,2$

\begin{tabular}{lll} 
Positif & 25 & 59,5 \\
Negatif & 17 & 40,5 \\
\hline
\end{tabular}

Pada penelitian ini, dari 42 keluarga, sesudah mengikuti FCC, persepsi keluarga terhadap kelahiran bayi prematur tergolong positif dengan rerata skor 15,0 $\pm 2,2$ dibandingkan sebelum mengikuti FCC yaitu 13,2 $\pm 1,8$

Selain itu, berdasarkan Tabel 2 menunjukkan persepsi keluarga tentang kelahiran bayi prematur mengalami perubahan antara sebelum dan sesudah dilakukan FCC. Sebelum diberikan penyuluhan, mayoritas orang tua bayi dengan kelahiran prematur memiliki persepsi negatif berupa kekhawatiran yang berlebihan dan kurangnya percaya diri dalam memberikan asuhan terhadap bayinya terutama di rumah pasa masa pasca perawatan rumah sakit. Setelah dilakukan intervensi berupa penyuluhan, persepsi orang tua dengan kelahiran prematur mengalami perubahan menjadi positif, berupa kekhawatiran yang lebih mampu diatasi dan meningkatnya kemampuan untuk dapat memberikan asuhan terhadap bayinya secara mandiri. T hasil analisis uji beda, diketahui nilai pearson chi square $=$ 98,746 dan nilai probabilitas (Asymp. Sig) diperoleh $0,001<0,05$, maka Ha diterima. Hal ini berarti ada perbedaan yang signifikan pada persepsi keluarga terhadap kelahiran prematur sebelum dan sesudah dilakukan FCC.

Tabel 2. Uji Beda terhadap Persepsi Keluarga Sebelum dan Sesudah FCC $(n=42)$

\begin{tabular}{cccc}
\hline $\begin{array}{c}\text { Persepsi } \\
\text { Keluarga }\end{array}$ & $\begin{array}{c}\text { Rerata Skor } \\
\text { (mean } \pm \text { SD) }\end{array}$ & $\begin{array}{c}\text { Pearson } \\
\text { Chi-square }\end{array}$ & $\begin{array}{c}\text { Asymp. Sig. } \\
\text { (P value) }\end{array}$ \\
\hline Sebelum $F C C$ & $13,2 \pm 1,8$ & 98,746 & 0,001 \\
Sesudah FCC & $15,0 \pm 2,2$ & & \\
\hline
\end{tabular}

\section{PEMBAHASAN}

Hasil uji beda terhadap keluarga bayi dengan kelahiran prematur sebelum diberikan penyuluhan FCC dan setelahnya mengalami perubahan dengan tHasil analisis uji beda, diketahui nilai Pearson Chi Square $=98,746$ dan nilai probabilitas (Asymp. Sig) diperoleh $0,001<0,05$, maka Ha diterima. Hal ini berarti ada perbedaan yang signifikan pada persepsi keluarga terhadap kelahiran prematur sebelum 
dan sesudah dilakukan FCC.

Sistem perawatan bayi di NICU memberikan dampak negatif bagi bayi dan orang tua. Upaya yang dapat dikembangkan untuk meminimalkan dampak tersebut yaitu dengan mengaplikasikan FCC. Langkah pertama upaya tersebut adalah dengan mengaplikasikan model FCC di ruang perawatan intensif neonatal melalui identifikasi kebutuhan orang tua. Menurut Ward (2011), kebutuhan orang tua dibagi kedalam 5 hal, yaitu: kebutuhan terhadap informasi (information), kebutuhan terhadap kepastian (assurance), kebutuhan terhadap kedekatan (proximity), kebutuhan terhadap kenyamanan (comfort), dan kebutuhan terhadap dukungan (support).(Aronoff \& Ward, 2011)

FCC merupakan model perawatan bayi di ruang perawatan intensif, dimana perawat melibatkan orang tua dalam merawat bayi yang sakit dengan bimbingan dan arahan dari perawat (Mattsson, Forsner, Castrén, \& Arman, 2013).

Perawatan bayi di ruang perawatan intensif bagi orang tua merupakan suatu situasi krisis yang mengakibatkan pengalaman stres, cemas, depresi, dan bahkan dapat mengalami posttraumatic stress (Cleveland, 2008). Hal ini terjadi karena secara psikologis orang tua belum siap untuk menghadapi penyakit kritis bayinya. Orang tua mungkin kecewa, mereka mungkin memiliki perasaan bersalah, kegagalan, putus asa, marah, ketidakberdayaan, dan hilangnya harga diri. Menurut hasil penelitian Shaw et al. dalam Cleveland (2014), sumber stres orang tua berawal dari perpisahan dengan bayinya yang baru lahir; ketidakmampuan untuk membantu, menjaga, dan merawat bayi; ketidakmampuan melindungi bayi dari nyeri; penggunaan teknologi serta alatalat di ruang intensif, dan kritisnya kondisi bayi.

Hospitalisasi dan pengalaman rawat inap bayi prematur di RS juga menimbulkan kecemasan tingkat tinggi dan gejala depresi pada orang tua, kehilangan kepercayaan diri dalam pengasuhan bayi, pengasuhan yang over protektif bagi bayinya, serta berdampak pada masalah kemunduran perkembangan dan tingkah laku bayi. Hasil penelitian menunjukkan bahwa sebelum dilakukan intervensi, orang tua lebih banyak memiliki tingkat pengetahuan kurang, sikap negatif, dan keterampilan yang kurang dalam melakukan perawatan bayi prematur, hal ini dipengaruhi oleh beberapa faktor antara lain informasi dari tenaga kesehatan, usia, tingkat pendidikan dan informasi yang didapat sebelumnya.

Dalam melakukan asuhan terhadap bayi prematur, selain meningkatkan pelayanan terhadap bayi, perawat harus memerhatikan kebutuhan orang tua terkait jaminan kepastian bayinya mendapatkan perawatan terbaik, penyampaian informasi dengan komunikasi terbuka, dan menjalin kontak dengan bayi. Dengan mengidentifikasi kebutuhan orang tua, dapat menuntun perawat mengintegrasikan kebutuhan orang tua ke dalam FCC sehingga orang tua dapat memenuhi kebutuhannya, mendapatkan kepuasan, dan meningkatkan kualitas hidup bayi.

FCC melibatkan orang tua dari berperan pasif menjadi berperan aktif untuk terlibat dalam perawatan anaknya (O'Brien et al., 2013). Berdasarkan berbagai hasil penelitian, didapatkan bahwa FCC merupakan model yang relatif aman dan mudah diterapkan. Selain itu, model ini juga terbukti dapat meningkatkan berat badan bayi, menurunkan behavioral stress pada bayi, meningkatkan kesejahteraan dan bonding attachment antara ibu dan bayi, menurunkan stres yang dialami orang tua terkait perawatan bayinya, menurunkan length of stay (LOS), dan membuat orang tua merasa lebih percaya diri dan kompeten dalam merawat bayinya setelah pulang ke rumah (Sikorova \& Kucova, 2012). Sehingga dengan diaplikasikannya FCC, terbukti dapat turut membantu meningkatkan kualitas hidup 
neonatus.

\section{SIMPULAN DAN SARAN}

Bayi dengan kelahiran prematur merupakan tantangan tersendiri bagi keluarga terutama orang tua untuk dapat melakukan asuhan kebidanan di rumah terutama pada masa pasca perawatan secara intensif yang dilakukan di rumah sakit. Selama ini, keluarga masih memiliki persepsi negatif terhadap kelahiran bayi prematur dengan memiliki kekhawatiran berlebihan dan kurangnya percaya diri dalam memberikan asuhan perawatan terhadap bayi secara mandiri.

Hasil penelitian menunjukkan terdapat perubahan persepsi pada keluarga bayi antara sebelum dan sesudah dilakukan intervensi. Penerapan perawatan berpusat pada keluarga membantu mengurangi dampak jangka panjang pada bayi prematur. Melalui penerapan perawatan berpusat pada keluarga, orang tua jadi memiliki persepsi positif, memiliki keyakinan akan kemampuan untuk merawat bayi dan siap ketika membawa pulang bayi mereka. Jika bayi prematur tidak dapat bertahan hidup, perawatan berpusat pada keluarga dapat menjadikan kebersamaan antara bayi dan orang tuanya menjadi lebih berkualitas.

\section{DAFTAR PUSTAKA}

Aronoff, C., a\& Ward, J. (2011). Family Meetings. Springer.

Behrman, R. E., \& Butler, A. S. (2007). Preterm birth: causes, consequences, and prevention (Vol. 772). National academies press Washington, DC.

Blencowe, H., Cousens, S., Modell, B., \& Lawn, J. (2010). Folic acid to reduce neonatal mortality from neural tube disorders. International Journal of Epidemiology, 39(suppl_1), i110-i121.
Bobak, I. M., Lowdermilk, D. L., Jensen, M. D., \& Perry, S. E. (2005). Buku ajar keperawatan maternitas. Jakarta: EGC.

Browne, J. V, \& Talmi, A. (2005). Family-based intervention to enhance infant-parent relationships in the neonatal intensive care unit. Journal of Pediatric Psychology, 30(8), 667-677.

Cleveland, L. M. (2008). Parenting in the neonatal intensive care unit. Journal of Obstetric, Gynecologic \& Neonatal Nursing, 37(6), 666-691.

Cockcroft, S. (2012). How can family centred care be improved to meet the needs of parents with a premature baby in neonatal intensive care? Journal of Neonatal Nursing, 18(3), 105-110.

Guttman, L. (1945). A basis for analyzing testretest reliability. Psychometrika, 10(4), 255-282.

Hockenberry, M. J., \& Wilson, D. (2007). Wong is nursing care of infants and children 8th Edition. Canada: Mosby Elsevier.

Mattsson, J., Forsner, M., Castrén, M., \& Arman, M. (2013). Caring for children in pediatric intensive care units: An observation study focusing on nurses' concerns. Nursing Ethics, 20(5), 528-538.

O’Brien, K., Bracht, M., Macdonell, K., McBride, T., Robson, K., O’Leary, L., ... Levin, A. (2013). A pilot cohort analytic study of Family Integrated Care in a Canadian neonatal intensive care unit. BMC Pregnancy and Childbirth, 13(1), $\mathrm{S} 12$.

Örtenstrand, A., Westrup, B., Broström, E. B., Sarman, I., Åkerström, S., Brune, T., ... Waldenström, U. (2010). The Stockholm Neonatal Family Centered Care Study: effects on length of stay and infant morbidity. Pediatrics, 125(2), e278e285. 
Penelitian, B. (2013). Riset kesehatan dasar (Riskesdas) 2013. Lap Nas, 2013(1), 384.

Riyanto, H. Y. (2009). Paradigma baru pembelajaran: sebagai referensi bagi guru/pendidik dalam implementasi pembelajaran yang efektif dan berkualitas. Kencana Prenada Media Group.
Sikorova, L., \& Kucova, J. (2012). The needs of mothers to newborns hospitalised in intensive care units. Biomed Pap Med Fac Univ Palacky Olomouc Czech Repub, 156(4), 330-336.

Soon, B. T. (2012). The Global Action Report on Preterm Birth. Geneva: World Health Organization. 
